\title{
The impact of the introduction of a formulary into a large Canadian private drug plan: an interrupted time- series analysis
}

\author{
Alan Cassels MPA, Michael R. Law PhD
}

\section{Abstract}

Background: Most private drug plans in Canada do not use a formulary, which leads to suboptimal drug use. We studied the impact of the adoption of the public formulary by a large private health benefits plan in British Columbia.

Methods: We studied the impact of a change by members of the BC Hospital Employees' Union to have their private drug plan mirror the public formulary as of June 2013. With data from Pacific Blue Cross, we conducted a before-and-after descriptive study using interrupted time-series analysis to study changes in covered drug costs and use for 18 months preceding and following the change.

Results: Our cohort averaged 66000 plan members and dependents over our study period. Following the implementation of the formulary, the number of prescriptions covered by the plan declined by 0.46 prescriptions per member per month ( $95 \%$ confidence interval -0.50 to -0.42 ), a decline of $23.8 \%$ at 1 year. This decreased plan spending by $\$ 13.2$ million over the 18 months after the coverage change, a $49.7 \%$ decline.

Interpretation: The adoption of the public formulary by a large private drug plan in BC substantially reduced drug plan expenditures and the volume of prescriptions paid for by the plan. Overall, these results suggest that carefully designed formulary changes could substantially reduce spending by private-sector drug plans on drugs that have more cost-effective therapeutic alternatives.

T n Canada, prescription drugs are covered through a mix of public and private insurance plans and out-of-pocket payments by patients. ${ }^{1}$ Most prescription drug expenditures come from private sources, either private benefits plans or out-of-pocket payments. ${ }^{2}$ Private insurers have traditionally made less use of major cost-control mechanisms than public drug plans in their plan management, ${ }^{3}$ which industry estimates suggest results in billions of dollars of excess spending every year. ${ }^{4}$ This has included a low use of formularies, which are positive lists that designate which drugs are covered by a plan. Formularies can encourage the use of treatments that are more cost-effective, provide leverage for drug plans to negotiate better prices with pharmaceutical companies $^{5}$ and discourage the use of medicines that lack a strong safety profile.

Private drug plans' avoidance of formularies in Canada might partly stem from a lack of understanding about their potential impacts. As very few plans have adopted formularies, there is a dearth of data about how they can affect drug costs and access. As such, when changes are proposed, plan sponsors, labour unions and employees have little guidance to foresee what those changes might mean to them. Further, as many unions will not have access to the underlying data or the skills necessary to analyze them, they have little basis on which to assess the trade-offs between drug coverage and other aspects of compensation. This is an important point to address given that about twothirds of an employee's extended health coverage (excluding dental coverage) is spent on pharmaceuticals. ${ }^{6}$ To address this gap in our knowledge, we studied the impact of the adoption of a public formulary by a large private health benefits plan in British Columbia on drug plan claims and expenditures.

Competing interests: Alan Cassels consulted for the Hospital Employees' Union during the conduct of the study and is a cofounder and the senior vice president of research and content at Quizzify, a private company working to increase health literacy in the US workforce. Michael Law consulted for the Hospital Employees' Union during the conduct of the study. He has also consulted for Health Canada and the Conference Board of Canada and acted as an expert witness for the Attorney General of Canada, outside the submitted work.

This article has been peer reviewed.

Correspondence to: Alan Cassels, cassels@uvic.ca

CMAJ Open 2019. DOI:10.9778/cmajo.20180124 


\section{Methods}

\section{Design}

We conducted a before-and-after descriptive study to examine changes in drug use and expenditures by private drug plan members and their dependents following the adoption of a public formulary using an interrupted time-series analysis. ${ }^{7}$ This is a methodologically appropriate approach as it examines longitudinal changes in outcomes of interest while controlling for pre-existing trends.

\section{Setting and policy intervention}

The Hospital Employees' Union is a large union based in British Columbia whose membership includes health care workers across a range of settings. Most members of the union receive non-optional private prescription drug benefits as part of their employment. On June 1, 2013, this private drug plan changed from covering all prescription drugs to only covering those covered by the BC Fair PharmaCare plan. Plan members were also required to follow the rules for reference pricing and prior authorization of many medicines, known as obtaining special authority. Coverage for several popular drugs was indefinitely grandfathered, meaning that plan members who had previously used these drugs maintained their coverage even though the drugs were delisted from coverage. This provision applied to plan members who had 1 or more claims for these medicines within the 6 months preceding the change (including duloxetine [Cymbalta], pregabalin [Lyrica], liraglutide [Victoza] and methylphenidate [Ritalin]). Several other public-sector bargaining associations in $\mathrm{BC}$ made a similar change at this time.

The change was announced to union members through a series of communications, including written notices and announcements at staff meetings, and through an Internet site and communications from the insurance carrier. Other annual drug coverage terms were the same before and after the formulary introduction, including a $\$ 100$ annual deductible (shared with other benefit types), $80 \%$ coverage of drug expenditures under $\$ 1000$ per family and $100 \%$ coverage over $\$ 1000$ per family. The plan would only reimburse the cost of generic equivalents, where available, and dispensing fees were capped at $\$ 9.00$ per prescription.

\section{Data sources}

We obtained anonymized drug benefits claims for all plan members and their dependents from the carrier for the plan, Pacific Blue Cross, for 18 months preceding and following the adoption of the formulary (December 2011 through November 2014). Our data set included the name and dose of the drug, the cost to the plan of the prescription and whether the drug was grandfathered into plan coverage. It also contained information on the number of plan members and dependents enrolled in the plan over the course of each month. We merged this with data from the BC PharmaCare formulary to ascertain whether the drug was on the public formulary and whether it required special authority approval.
Finally, we determined the drug class for each prescription record using codes for the Anatomical Therapeutic Chemical Classification System contained in Health Canada's Drug Product Database. ${ }^{8}$

\section{Outcome variables}

Our outcome variables included (a) the number of prescriptions obtained per member per month, (b) differences in the number of prescriptions based on formulary designation, (c) the number of grandfathered therapies obtained per month and (d) the total per-member per-month plan expenditures.

\section{Statistical analysis}

We fit our segmented regression models using a generalized least squares model and incorporated appropriate autocorrelation parameters for each model on the basis of several diagnostic criteria, including residual inspection, autocorrelation and partial autocorrelation plots, and Durbin-Watson test results. ${ }^{9}$ Our models included terms for the existing level and trend in the outcome, as well as changes in both the level and trend, and they also included an indicator variable for the month of January, as use and cost decline with the rollover of deductibles in the public plan in that month. The underlying assumption in such models is that the outcome would have continued on its existing trajectory in a linear fashion absent the formulary change. We did not conduct any sensitivity analyses.

\section{Ethics approval}

As this study used anonymized secondary data, ethics approval was not necessary.

\section{Results}

\section{Overall utilization and cost}

The total number of people covered by the plan, including dependents, averaged 66000 over the study period (it ranged between 62291 and 71669 in each month). Overall, drug spending during the 36-month period we examined totalled $\$ 41.9$ million, with 1.25 million prescriptions eligible for coverage by the benefits plan.

\section{Prescription use}

The total number of prescriptions paid for by the benefits plan over the 36-month period was 1252383 , of which 733737 were filled before the formulary switch and 518646 after. As shown in Figure 1, we found an immediate decrease in the number of prescriptions per member per month paid for by the plan $(-0.46,95 \%$ confidence interval $[\mathrm{CI}]-0.50$ to -0.42 ). We also found an increase in the trend of 0.010 per member per month thereafter (95\% CI 0.007 to 0.013 ). Taken together, these findings represent a $23.8 \%$ reduction in the number of prescriptions paid for at 1 year after the coverage change.

Table 1 shows the largest reductions in the number of prescriptions for individual ingredients (defined at the Anatomical Therapeutic Chemical-5 level) after the formulary 


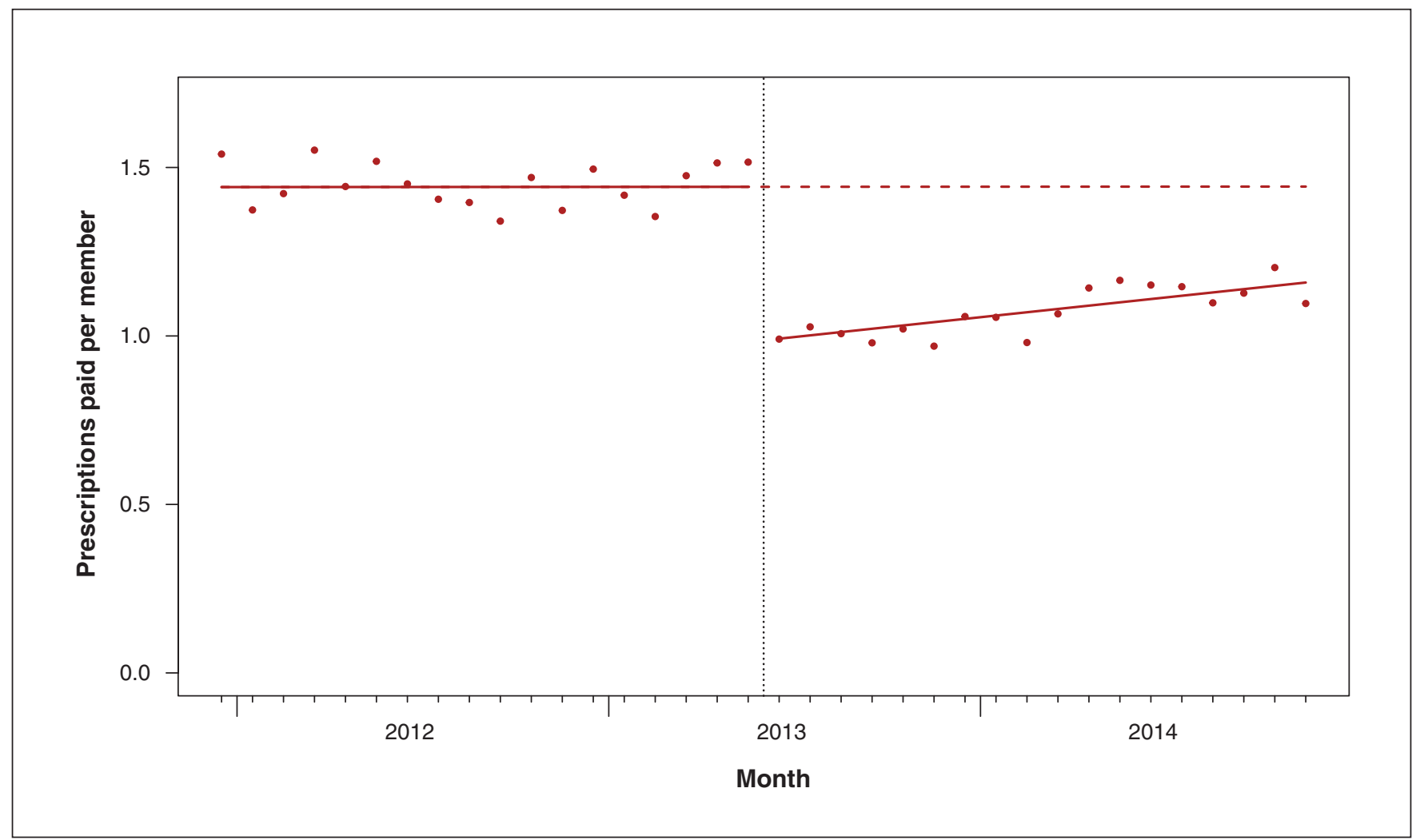

Figure 1: Average monthly number of prescriptions per member where at least a portion was paid by the benefits plan, before and after a change to the provincial formulary in June 2013.

\begin{tabular}{|lcccc|}
\hline $\begin{array}{l}\text { Table 1: Top } 10 \text { medicines in terms of reductions in prescription volume following the } \\
\text { adoption of the Fair PharmaCare formulary by the drug benefits plan of the BC Health } \\
\text { Employees' Union }\end{array}$ & \multicolumn{3}{c|}{} \\
\cline { 2 - 4 } Ingredient & No. of prescriptions & \\
\hline Zopiclone & Before & After & Difference & \% change \\
\hline Pantoprazole & 18912 & 1953 & -16959 & -89.7 \\
\hline Rabeprazole & 10091 & 2655 & -7436 & -73.7 \\
\hline Esomeprazole & 9116 & 1782 & -7334 & -80.5 \\
\hline Bupropion & 8057 & 1312 & -6745 & -83.7 \\
\hline Tramadol, combinations & 8133 & 2192 & -5941 & -73.0 \\
\hline Mometasone & 6281 & 732 & -5549 & -88.3 \\
\hline Celecoxib & 7051 & 1613 & -5438 & -77.1 \\
\hline Pregabalin & 4845 & 281 & -4564 & -94.2 \\
\hline Gliclazide & 3928 & 534 & -3394 & -86.4 \\
\hline
\end{tabular}

change. The largest declines were for zopiclone (anxiety and sleep), pantoprazole, rabeprazole and esomeprazole (gastroesophageal reflux), bupropion (depression and smoking cessation) and mometasone (asthma and seasonal allergies). As shown in Table 1 , many of the changes were substantial, with reimbursed drug use dropping by $80 \%$ or more for many ingredients.
As shown in Figure 2, the number of prescriptions per member per month for grandfathered medicines paid for by the plan dropped substantially: we found a level decrease of 0.015 prescriptions per member per month ( $95 \%$ CI -0.017 to -0.014 ) and no statistically significant increase in the trend thereafter. This represents an $83.8 \%$ reduction in the coverage of these grandfathered medicines at 1 year after the formulary change. 


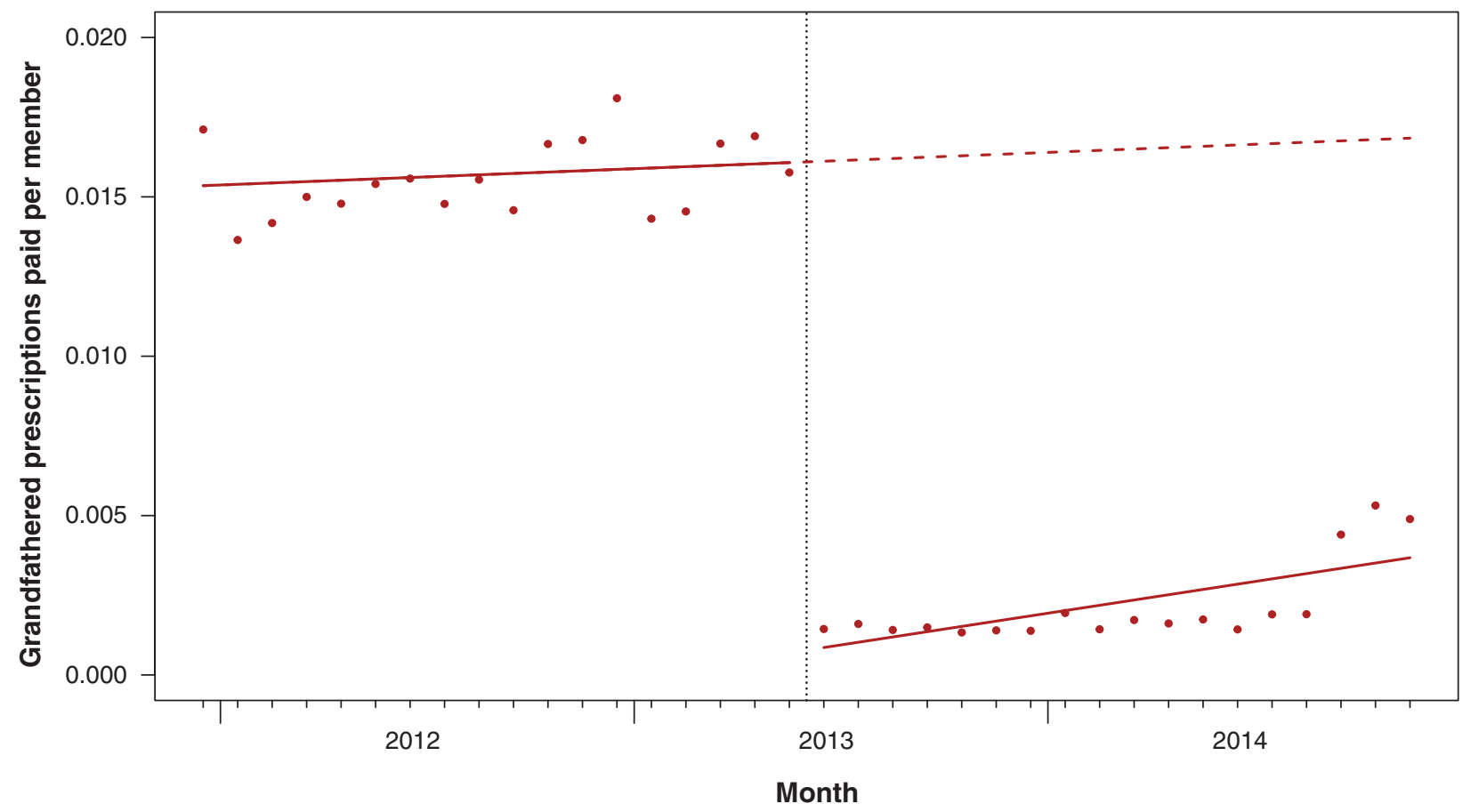

Figure 2: Interrupted time-series analysis of the number of prescriptions per member for grandfathered medications paid for by the plan before and after the change to the public formulary in June 2013.

\section{Prescription use by formulary designation}

Unsurprisingly, our analysis showed substantially different impacts of the formulary change, depending on whether the drugs affected were on or off the formulary. Figure 3 shows the interrupted time-series results for each class separately. We found a small reduction in the number of prescriptions for PharmaCare benefits of -0.03 per member per month (95\% CI -0.057 to -0.004$)$, but this was offset by an increase in the trend of 0.005 (95\% CI 0.003 to 0.007 ) that led to an overall increase past the 6-month time point.

In contrast, the level of both drugs not covered as benefits and drugs requiring special authority dropped substantially. The level of nonbenefit treatments immediately dropped to nearly 0 , with a level change of -0.18 prescriptions per member per month $(95 \% \mathrm{CI}-0.20$ to -0.17$)$. We also found a very small yet statistically significant increase in the trend of 0.00071 prescriptions per member per month (95\% CI 0.000033 to 0.0014). Overall, this represents a predicted drop of $89.8 \%$ for nonbenefit drugs at 1 year after the formulary change.

Similarly, for drugs requiring special authority, we found an immediate level drop of -0.25 prescriptions per member per month (95\% CI -0.26 to -0.24$)$. We also found an increase in the trend of 0.0039 prescriptions per member per month afterward (95\% CI 0.0032 to 0.0045$)$. Despite this increase in trend, however, the overall predicted utilization of special authority products remained $65.0 \%$ lower at 1 year than would have been expected on basis of the pre-existing level and trend.

\section{Prescription drug plan expenditures}

As shown in Figure 4, there was a decreased plan expenditure of $\$ 33.11$ per member per month after the adoption of the public formulary (95\% CI -38.78 to -27.44$)$. The estimated change in trend was in the opposite direction, with an estimated increase of $\$ 0.60$ per member per month (95\% CI 0.058 to 1.15$)$. Considered together, these findings represent an overall $\$ 13.2$ million reduction in spending on the drug benefits plan over the 18 months we studied - a $49.7 \%$ decrease in the \$26.7 million in spending that was predicted over that time period.

\section{Interpretation}

For many years, private drug benefits plans in Canada have used limited cost-control mechanisms, but as year-over-year costs continue to increase markedly, interest in cost-control measures has also grown. We found that a switch to a public drug formulary for a large union plan in BC reduced that union's drug benefit costs substantially - on the order of $50 \%$. We also found reductions in the volume of prescriptions covered by the plan, including for listed drugs that required special authority.

Our findings reinforce the use of formularies as an effective mechanism by which drug plans can control costs. ${ }^{10,11}$ They also suggest that formularies can be used to steer benefits plan members toward more economical and more appropriate 


\section{Research}

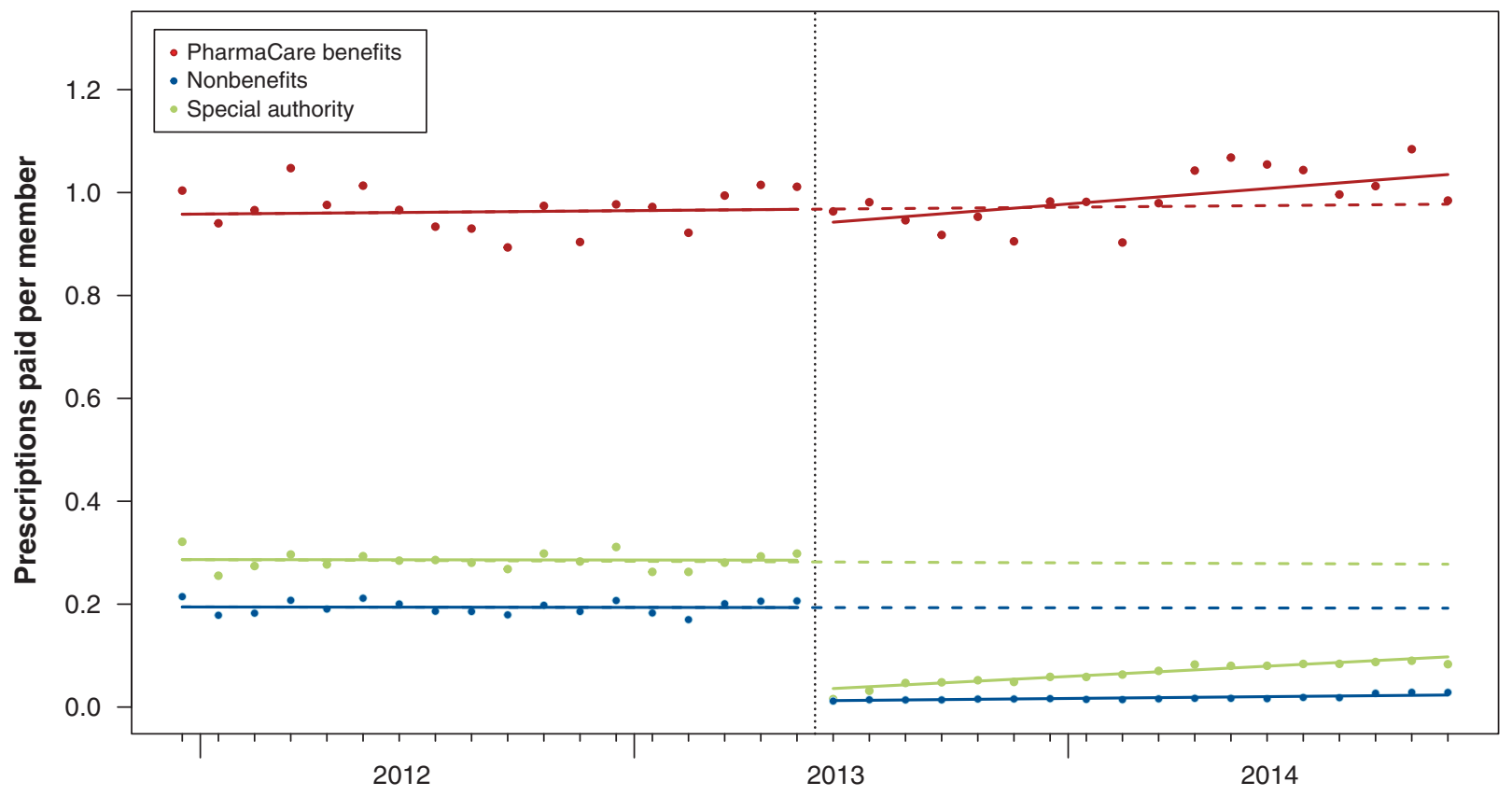

Month

Figure 3: Average number of prescriptions for members before and after the change to the PharmaCare formulary in June 2013, by PharmaCare benefit type.

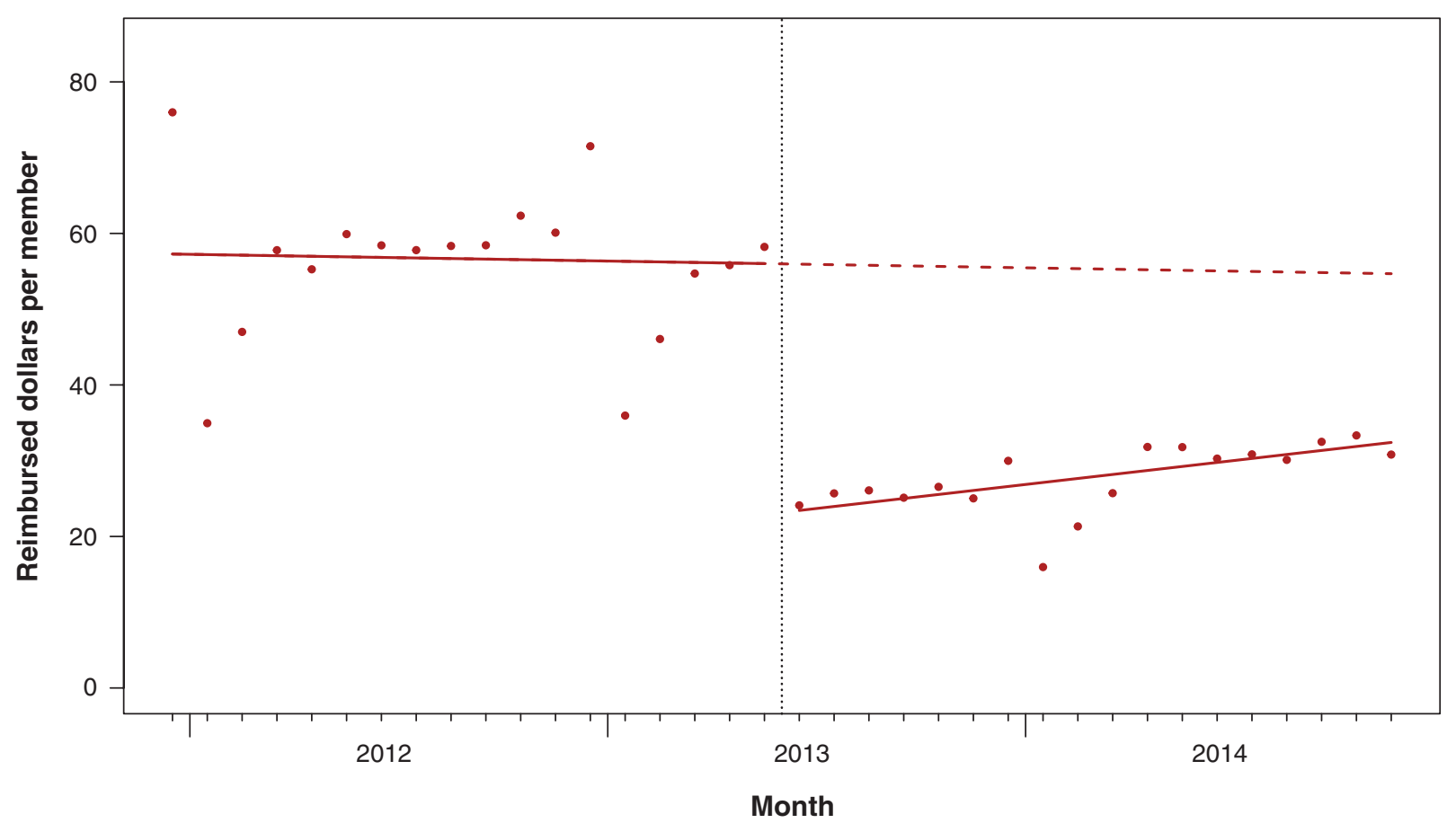

Figure 4: Interrupted time-series analysis of reimbursed dollars per member before and after the change to the public formulary in June 2013. 
medicines for various health conditions. The medicines that declined in use the most substantially following the formulary change included drugs with the potential for addiction (zopiclone, tramadol), drugs not therapeutically or economically superior to alternatives (esomeprazole, duloxetine, liraglutide) and drugs not recommended by guidelines for long-term continuous use (pantoprazole, rabeprazole). Many of these large reductions in use were for drugs that required special authority, a finding that is consistent with the impact of other prior authorization policies. ${ }^{12}$ However, the longer term increase in the trend we observed for drugs requiring special authority suggests that plan members who were affected by being prescribed special authority drugs were probably quickly becoming educated about how to navigate the new coverage rules. The grandfathering of people on existing therapies was intended to mitigate this, but we observed major declines in the reimbursement of these drugs as well.

\section{Limitations}

Our analysis has limitations that are worth noting. First, while we are unaware of any changes affecting plan employees around the time of the formulary change, there is the potential for bias in our estimates if such changes did occur and these confounders were not included in our models. However, they would have to have had a very large influence on drug use to change our interpretation of our findings. Although a control group could have provided a helpful comparison in this regard, comparable data from another plan were not available to us. Unfortunately, our data did not enable us to ascertain precisely how plan members changed their behaviour after the formulary change. As we only had access to drug claims made to the plan, it was not possible to ascertain whether members (a) paid out of pocket, (b) used spousal drug plan coverage or (c) stopped therapies altogether. Although we cannot assess the occurrence of these alternatives, if members did stop therapy this may have been detrimental (notwithstanding the potential for harm from many of these same drugs). This also limited our ability to assess changes to other drugs with therapeutic equivalence. Further, our findings may have limited generalizability and may not be applicable to jurisdictions that do not have public income-based coverage schemes such as BC. However, we feel it is worth noting that several other provinces have similar widely available catastrophic coverage plans (e.g., Ontario's Trillium Drug Program and Manitoba's Pharmacare Program). ${ }^{1}$ Finally, the degree of savings from such changes critically depends on the current level of drug use in the plan, which may differ for other employee groups.

\section{Conclusion}

We found that the adoption of the public formulary by a large private benefits plan in $\mathrm{BC}$ led to a significant reduction in plan expenditures. This provides further evidence to Canadian employers and labour unions about the expected magnitude of savings offered by drug plan modifications in collective bargaining activities. It also provides a simple path to implementing such changes, as public formularies are easily available and are widely familiar to practising physicians. Future studies should investigate the overall impact on drug use and the potential for cost-shifting to patients. Our results also speak to the need for drug plan managers to carefully anticipate potential changes and communicate thoroughly with their members. The large drops we saw in grandfathered therapies indicate some degree of communication difficulties around the formulary change. Although such changes have proven controversial in some instances, the scope for savings for Canadian employers and their employees appears to be substantial.

\section{References}

1. Daw JR, Morgan SG. Stitching the gaps in the Canadian public drug coverage patchwork? A review of provincial pharmacare policy changes from 2000 to 2010. Health Policy 2012;104:19-26.

2. National health expenditure trends, 1975 to 2016. Ottawa: Canadian Institute for Health Information; 2016.

3. Kratzer J, McGrail K, Strumpf E, et al. Cost-control mechanisms in Canadian private drug plans. Healthc Policy 2013;9:35-43.

4. Sawa T, Ellenwood L. Billions wasted on drug spending in Canada, research shows. CBC News — Fifth Estate 2017 Jan. 12. Available: www.cbc.ca/news/ health/drug-costs-canada-1.3927989 (accessed 2018 Apr. 3).

5. Morgan SG, Thomson PA, Daw JR, et al. Canadian policy makers' views on pharmaceutical reimbursement contracts involving confidential discounts from drug manufacturers. Health Policy 2013;112:248-54.

6. Canadian life and health insurance facts - 2017 edition. Ottawa: Canadian Life and Health Insurance Association Inc.; 2017. Available: http://clhia.uberflip. com/i/878840-canadian-life-and-health-insurance-facts-2017/17? (accessed 2018 Jan. 23).

7. Wagner AK, Soumerai SB, Zhang F, et al. Segmented regression analysis of interrupted time series studies in medication use research. 7 Clin Pharm Ther 2002;27:299-309.

8. Drug product database online query. Ottawa: Health Canada; updated 2018 Dec. 14. Available: https://health-products.canada.ca/dpd-bdpp/index-eng.jsp (accessed 2018 Jan. 23).

9. Penfold RB, Zhang F. Use of interrupted time series analysis in evaluating health care quality improvements. Acad Pediatr 2013;13(Suppl):S38-44.

10. Huskamp HA, Deverka PA, Epstein AM, et al. The effect of incentive-based formularies on prescription-drug utilization and spending. N Engl f Med 2003;3 49:2224-32.

11. Huskamp HA, Epstein AM, Blumenthal D. The impact of a national prescription drug formulary on prices, market share, and spending: lessons for Medicare? Health Aff (Millwood) 2003;22:149-58.

12. Soumerai SB. Benefits and risks of increasing restrictions on access to costly drugs in Medicaid. Health Aff (Millwood) 2004;23:135-46.

Affiliations: Faculty of Human and Social Development (Cassels, Law), University of Victoria, Victoria, BC; Centre for Health Services and Policy Research (Law), School of Population and Public Health, University of British Columbia, Vancouver, BC

Contributors: Both authors contributed to study conception and design. Michael Law carried out the analyses. Both authors drafted and revised the manuscript, gave approval of the final version for publication and agreed to act as guarantors of the work.

Funding: This analysis was funded by the British Columbia Hospital Employees' Union. Michael Law received salary support through a Canada Research Chair in Access to Medicines and a Michael Smith Foundation for Health Research Scholar Award.

Supplemental information: For reviewer comments and the original submission of this manuscript, please see www.cmajopen.ca/content/7/3/ E472/suppl/DC1. 